\title{
IMPLEMENTING A BALANCED SCORECARD METHODOLOGY IN SMES
}

\author{
Siniša Jankovićit, \\ Nikola Škobo', \\ Mile Stanišić ${ }^{2}$ \\ ${ }^{1}$ University of Sinergija, \\ Bijeljina, The Republic of Srpska, B\&H \\ ${ }^{2}$ Singidunum University, \\ Belgrade, Serbia
}

Correspondence:

Siniša Janković

e-mail:

sjankovic@sinergija.edu.ba

\begin{abstract}
:
Traditional systems for performance measurement are mainly confined to monitoring financial indicators as the only relevant criteria. Various surveys conducted worldwide have shown that relying solely on financial indicators is insufficient and leads to long-term decline in the overall performance of the company. By applying a balanced scorecard list of criteria, the company is permitted to observe its business from multiple perspectives that show a comprehensive picture of enterprise performance. This methodology has proven to be very successful in large enterprises, while in small and mediumsized enterprises its use has not been sufficiently explored. In this paper, we analyze the compatibility, applicability and efficacy of the balanced scorecard methodology for performance measurement in small and medium-sized enterprises.
\end{abstract}

Key words:

Balanced Scorecard, performance measuring, small and medium-sized enterprises

\section{INTRODUCTION}

The methodology of Balanced Scorecard has been developed to allow an efficient integration of many variables that must be considered when measuring the performance of companies. Balanced Scorecard is a set of criteria that allows managers a holistic view of the organization. Traditional performance measurement systems place special emphasis on purely financial indicators and ignore the others. Balanced Scorecard as an innovative methodology introduces a number of other indicators that should allow the all-assessment of the performance of the organization. In addition to the financial perspective, balanced scorecard introduced perspective customers, internal processes, as well as learning and development, which are of equal importance to the organization. The initial methodology devised by Kaplan and Norton is developed for large companies, but application in SMEs is also possible with some adjustments, taking into account the specific characteristics of SMEs.

\section{ABOUT BALANCED SCORECARD}

Balanced scorecard (BSC) is a management system that can activate the energy, skills and specific knowledge that people in the organization possess and these can be directed towards the fulfillment of long-term 
strategic goals. Strategic map provides a framework for describing how the strategy links intangible assets to the process of value creation. BSC is a system of measurement of results and performances of the company and involves setting up financial and strategic company goals and measuring their achievement. Setting financial and strategic objectives includes short-term and longterm goals. BSC helps organizations to resolve three major issues: organizational effectiveness measurements of success, increasing intangible assets and challenges of implementing the strategy. These are the three main factors affecting each organization. The measuring system of organization makes a powerful impact on people's behavior inside and outside the organization. In order for the companies to be able to survive in the information age competition, they must use measurement and control systems derived from their strategies.

To be able to clearly monitor what is happening in each of these prespectives, it is necessary to draw up a strategic map. Strategic map structure makes four perspectives and their causal connections. The structure according to Kaplan and Norton includes: [3]

- learning and growth perspective,

- internal proccesses perspective

- customer and

- financial perspective.

Each generic measures must be defined to explain and, depending on the type of activities and strategic goals, form the measurement system and monitor performance. BSC translates the mission and strategy in the tasks and criteria, organized into the four perspectives. By defining the outcomes that the organization wants as well as the drivers that lead to these outcomes, managers direct the energy, skills and specific knowledge of people in the organization towards long-term goals.

Learning and growth perspective describes the intangible assets of the company and its role in the strategy. Intangible assets are: [3]

- human capital - availability of qualified personnel, talent and knowledge necessary to implement the strategy.

- information capital - availability of information systems, network and infrastructure necessary for establishing the strategy.

- organizational capital - what kind of environment and organization is required to maintain the process changes required to implement the strategy.

Making BSC involves three main categories for learning and growth perspective: opportunities, employ- ees, features of information systems, motivation and initiative. The process of measuring the readiness of human capital begins with identifying the necessary skills by individuals who carry out important internal processes of the organization's strategic map. The organization first identifies a competent profile, which describes the fundamental requirements for the groups of tasks that define the strategic success. Competence profile describes the knowledge, skills and values that a person employed at a particular position is necessary to have.

Internal perspective identifies key processes that are expected to have the greatest impact on strategy. Particularly interesting are the following four groups of processes:[4]

- operational processes,

- management processes to customers,

- innovation processes,

- regulatory and social processes.

Operational processes are the primary activities of Porter's value chain. The link between strategy and operations requires a comprehensive framework that integrates sales and production planning, resource allocation, dynamic forecast (budget) in operating and capital expenditures and financial forecasting profitability. Mass production and delivery of standard products and services must be replaced by a flexible, dynamic and highquality delivery of innovative products and services that can be individualized for targeted customer segments.

The company develops management processes by identifying the main tasks, which encourage achievement of the objectives in connection with customers, as well as financial goals, then assigns the key performance indicators that encourage excellence in the process. In order to improve the process of design and development, employees are required to have process indicators that motivate them, but also monitor whether the existing projects achieve success.

Management processes deepen customer relationship with the target group through selection, recruiting and retaining of customers. They also increase the volume of work. Customer retention derives from excellent services.

Customers perspective describes how the organization will create sustainable value for the customers. This perspective includes several well-known benchmarks in relation to the customers: customer satisfaction, recruiting, customer retention and market share.

Financial perspective describes the tangible results such as return on investment, value for shareholders, 
profitability and revenue growth. Its ultimate goal is to bring profit to the maximum. The financial perspective is the crown of the previous perspectives. Basically, the financial strategies are simple. Businesses can gain more money: higher sales and reducing costs.

\section{FITTING BALANCED SCORECARD TO SMES}

In their research, professors Kaplan and Norton have expressed the opinion that the BSC methodology is not designed exclusively for large companies. It is shown that small and medium-sized enterprises can also benefit greatly from the use of this model. Following the publication of this research, a number of authors have been inspired to redesign this innovative model in order to adapt it to small and medium enterprises. A large number of researchers confirmed the hypothesis presented by Norton and Kaplan: the hypothesis that it is possible to adapt this model to the specific characteristics of SMEs. The conclusions of this study point out that even in some segments, it is easier to implement this methodology in SMEs than in large enterprises, as their size can be used as a major advantage to confirm this thesis. This research emphasized the importance of the BSC for SMEs in terms of the introduction and improvement of the system for performance measurement, as well as issues related to the strategy of the company.

The biggest problem when it comes to the basic model for implementation of Balanced Scorecard in SMEs is the lack of their strategies. Most SMEs do not give enough importance to the strategy, while a large number of them have not even formulated the strategy. Because BSC is the system for measuring the performances closely linked to the strategy, it is clear that this is the biggest problem related to the implementation of the BSC. The actual model for implementation proposed by Kaplan and Norton is based on the top-down logic. This means that the base point in the implementation of the BSC is actually formulating the mission and vision of the company, which should enable the commencement of the process of performance measurement.

This methodology has been developed for large companies and its application in SMEs is inadequate. One of the most redesigned models for implementation in SMEs is incremental model developed by Hudson and Smith. With this model the whole process of implementing BSC is placed in a circle: [2]

- Name: the main strategic objective to focus upon is immediately identified;
- Act: the performance measures connected with that strategic objective are identified, along with the improvement actions needed;

- Use: the measurement system is implemented and the improvement actions are activated;

- Learn: the target achievement is monitored and, at the same time, the adequacy of the selected measures is assessed.

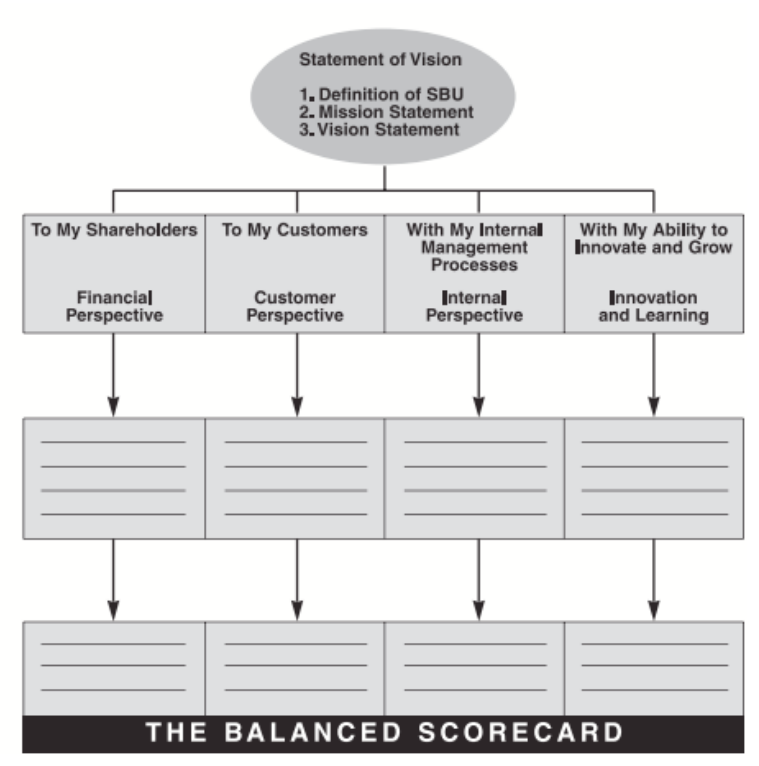

Figure 1. Linking Meauserments to Strategy[3]

In addition to this model, it is important to mention the model developed by authors Biazzo S. and P. Garengo, which is based on a circular approach for the implementation with four basic steps that should be followed when implementing the BSC in SMEs. This is one model that fits in SMEs, taking into account their specific characteristics. [1]

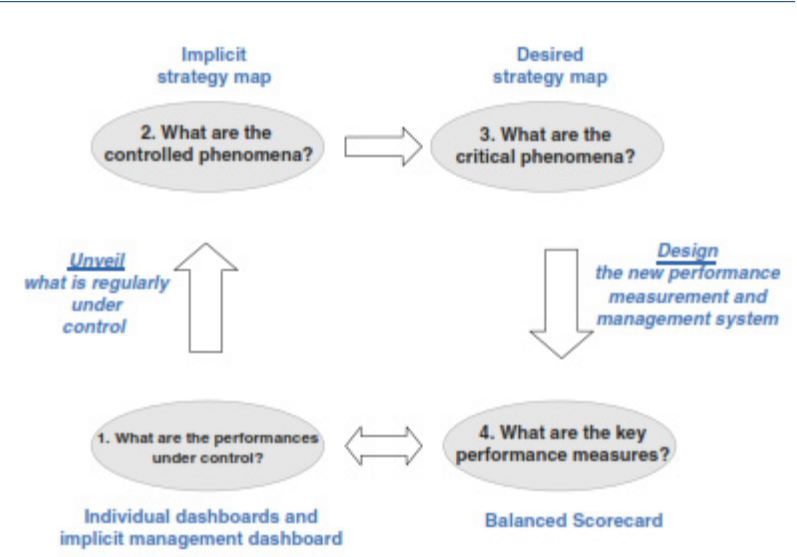

Figure 2. A circular approach to the implementation of the $\mathrm{BSC}[5]$ 
In the first step, it is necessary to determine the performances that have already been under the control of the company. This step leads to the development of implicit strategic map. It is necessary to develop the desired strategic map which sets new performance measures that are essential for the company. In the process of creating the BSC, it is necessary to allocate individual dashboards. After this step, a circular process that enables control of BSC execution begins.

When it comes to implementation of the BSC in small and medium enterprises in Bosnia and Herzegovina, the situation is specific. Bosnia and Herzegovina is a country in transition where the management systems are at a low level of development. Most small and medium enterprises in Bosnia and Herzegovina continue to rely exclusively on financial indicators as the basis for decison-making.

\section{SOFTWARE AS THE BASIS FOR SUCCESSFUL IMPLEMENTATION BSC IN SMES}

When it comes to using software for BSC, the main problem with SMEs are mostly high prices of software. SMEs are generally not able to buy software that is available in the market place. Therefore, they usually resort to the use of cheaper varieties.

Here we will introduce three open source software that companies can use for managing BSC.

1. BSPG Balanced Scorecard. This is a complete BSC environment running on PostgreSQL and comparable to many similar commercial software for measurement-based management. It manages a company strategy through objectives, measures and targets, reports and graphics.

2. BambooBSC Balanced Scorecard is an open source BSC for creating, managing BSCs vision, perspectives, strategic of themes, objectives of strategy, key performance indicators, personal and organization performance analysis, strategy map, KPI report, personal and organization $\mathrm{BC}$ report.

3. cBSC collaborative balanced scorecard is a collaborative tool to support the strategic development of a company or public BSC. All employees of a business unit can develop together a balanced scorecard using cBSC tools.[7]

Also, a large number of SMEs are now relying on the use of Excel software of Microsoft Office, which al- lows a relatively good track and manage of BSC. A good basis for understanding the potential of this software for BSC use is the book of the author Ron Person "Balanced Scorecards and Operational Dashboards with Microsoft Excel", that shows the possibilities for combining the benefits of balanced scorecards, operational dashboards, performance managements, and data visualization and then implementing them into Microsoft Excel. [6]

\section{CONCLUSION}

Balanced scorecard is an innovative methodology for performance measurement developed for large companies. However, it can also be implemented in the small and medium-sized enterprises. Due to the fact that integrated management systems in Bosnia and Herzegovina remained poor and inadequate within an ever-changing environment, the need for such system proved to be of crucial importance. With the use of systems such as the BSC, SMEs can set up an effective framework for the establishment of integrated system for performance measurement.

\section{REFERENCES}

[1] Biazzo, S. and Garengo, P. (2012) Performance Measurement with the Balanced Scorecard. New York: Springer.

[2] Hudson, S. and Smith, D. (2007) Implementing strategically aligned performance measurement in small firms. International Journal of Production Economics 106.2, 393-408. DOI: 10.1016/j. ijpe.2006.07.011

[3] Kaplan, R. and Norton, D. (1996) The balanced scorecard: translating strategy into action. Boston: Harvard Business Press.

[4] Kaplan, R. and Norton, D. (1996) Using the balanced scorecard as a strategic management system. Harvard business review 85.7/8, 150.

[5] Patrizia, G. and Biazzo, S. (2012) Unveiling strategy in SMEs through balanced scorecard implementation: A circular methodology. Total Quality Management \& Business Excellence 23.1, 79-102. DOI:1 0.1080/14783363.2011.637800

[6] Person, R. (2013) Balanced scorecards and operational dashboards with Microsoft Excel. New Jersey: John Wiley \& Sons.

[7] Predictive analytics today http://www.predictiveanalyticstoday.com/open-source-balanced-scorecardsoftware/ 